\title{
Агроэкология
}

\section{МЕТОДОЛОГИЯ ОЦЕНКИ РИСКОВ ДЛЯ АГРОЭКОСИСТЕМ В УСЛОВИЯХ ТЕХНОГЕННОГО ЗАГРЯЗНЕНИЯ}

\author{
А.В. ПАНОВ, Т.В. ПЕРЕВОЛОЦКАЯ
}

В настоящее время перед мировым научным сообществом стоит задача выявления и минимизации экологических рисков, связанных с влиянием на экосистемы, в особенности аграрные, антропогенных факторов (А.А. Музалевскиий с соавт., 2011). Основополагающая роль оценки экологического риска заключается в определении вероятности возникновения эффектов различной природы в экосистемах в результате влияния техногенных (радиационные, химические, биологические) факторов и принятии мер по предотвращению их негативного воздействия. Наиболее часто источниками загрязнения агроэкосистем становятся: аэральные выпадения от выбросов промышленных предприятий и транспорта, загрязнение водоемов промышленными сточными водами, осадки сточных вод, органические и минеральные удобрения и средства защиты растений, отвалы золы, шлака, руд, шламов (S.C. Barman с соавт., 2000; Yu.N. Vodyanitskii с coaвт., 2011; E.C. Rowe с соавт., 2015). Как правило, риски при этом оцениваются ситуативно, а используемые методы применимы для конкретного фактора (агента), действующего в анализируемом случае, и объекта его воздействия. Целью представленного теоретического исследования была разработка единой методологии оценки агроэкологических рисков, обусловленных последствиями техногенного загрязнения. В предлагаемой методологии использовано математическое моделирование. Ее основу составляют принципы и критерии минимизации угроз безопасности при техногенных загрязнениях аграрных экосистем. В качестве главного источника техногенного воздействия рассматривается атмосферный путь поступления загрязнителей, при этом учитывается различный временной характер такого воздействия - от острого (включая аварийные чрезвычайные ситуации) до хронического. Для определения агроэкологических рисков в качестве критерия предложена оценка снижения продуктивности компонентов агроэкосистемы как важнейшего интегрального показателя развития живых организмов. Методология состоит из четырех этапов оценки агроэкологических рисков: идентификация опасности - обобщение доступной информации об агроэкосистеме, установление источников техногенного воздействия и их природы, выделение «критических» компонентов агроэкосистемы; оценка воздействия - измерение или расчет интенсивности и продолжительности, а также путей воздействия техногенных факторов на компоненты агроэкосистемы; оценка зависимости «доза-эффект» - определение количественной связи между степенью воздействия техногенных факторов на компоненты агроэкосистемы и вероятностью возникновения в них негативных эффектов; характеристика риска - анализ степени надежности полученных данных, описание рисков от отдельных техногенных факторов и их сочетаний, а также оценка вероятности возможных неблагоприятных эффектов для компонентов агроэкосистемы. Обоснован выбор метода оценки агроэкологических рисков (детерминистский, вероятностные 1-го и 2-го типа, интегральный вероятностный) в зависимости от степени информационного обеспечения показателей, включая критерии оценки риска и степень техногенного воздействия. При характеристике риска осуществляется его классификация и оценка соответствия приемлемому экологическому уровню (использование величин предельно допустимых концентраций и полулетальных доз). В рамках каждого этапа учитываются неопределенности при оценке агроэкологических рисков. Предложен алгоритм реализации методологии оценки агроэкологических рисков: 1 - анализ базы данных и формирование выборок, включающих значения рассматриваемых негативных эффектов при различной степени техногенного воздействия; 2 - определение метеорологических параметров модели поведения загрязнителей в атмосфере для конкретных условий выброса; 3 - определение величины осаждения загрязняющих веществ на земную поверхность расчетными или экспериментальными методами в зависимости от особенностей техногенного воздействия; 4 - определение величины загрязнения радионуклидами или химическими токсикантами компонентов агроэкосистемы расчетными или экспериментальными методами; 5 - расчет или измерение степени воздействия радионуклидов или химических токсикантов на компоненты агроэкосистемы. Предложенные подходы к разработке моделей, необходимых для оценки агроэкологического риска, применимы для решения широкого класса экологических задач.

Ключевые слова: аграрная экосистема, сельскохозяйственная продукция, тяжелые металлы, радионуклиды, техногенный фактор, компоненты агроэкосистемы, степень воздействия, доза-эффект, математические модели.

Развитие ядерной энергетики, металлургии, транспорта, химической и других отраслей промышленности, деятельность которых (включая тех- 
ногенные аварии) приводит к загрязнению окружающей среды, ставит перед мировым научным сообществом задачу выявления и минимизации экологических рисков, связанных с влиянием на экосистемы, в особенности аграрные, антропогенных факторов (1-3). В настоящее время экологический риск выступает как приоритетный обобщенный показатель, на основе которого принимаются важные управленческие решения, что требует разработки методов его расчета, невозможной без понимания фундаментальных механизмов организации и функционирования экосистем (4-6). Использование таких методов позволит не только дать количественную оценку экологического риска и значительно снизить ее неопределенность, но и разработать способы управления им в экосистемах на всех уровнях организации (7-9). Основная роль оценки экологического риска заключается в определении вероятности возникновения эффектов различной природы в экосистемах в результате влияния техногенных (радиационные, химические, биологические) факторов для принятия мер по предотвращению негативных воздействий (10-12).

Аграрные экологические системы представляют собой сообщества культурных растений и животных и среды их обитания, искусственно созданные человеком с целью получения сельскохозяйственной продукции. От качества производимых продуктов питания напрямую зависит здоровье человека (13-15). Это обусловливает необходимость ограничения и прогнозирования возможного негативного воздействия техногенных факторов разной природы на сельскохозяйственные земли и продукцию (16-18). Наличие в почве сбалансированного состава микроэлементов (включая тяжелые металлы) - важная основа для оптимального развития сельскохозяйственных растений (19-21). В то же время повышенная концентрация тяжелых металлов в почве негативно влияет на физиологические процессы в растениях (22-24). Наиболее часто основными источниками загрязнения агроэкосистем становятся аэральные выпадения от выбросов промышленных предприятий и транспорта, промышленные сточные воды, осадки сточных вод, органические и минеральные удобрения и средства защиты растений, отвалы золы, шлака, руд, шламов (25-27).

Важные особенности современной экологической ситуации в агросфере - одновременное влияние на компоненты агроэкосистем большого числа факторов разной (физической, химической и биологической) природы, невысокая степень и хронический характер воздействия (28-30). Повышенные концентрации поллютантов негативно сказывается на продуктивности агроэкосистем, которая в значительной мере определяет их устойчивость (31-33). В связи с этим необходимо оценить вероятность возникновения обратимых или необратимых изменений в структуре агроэкосистемы и функциях ее компонентов в ответ на техногенное воздействие (34-36).

К качественными и количественными показателям, характеризующим вероятность негативных эффектов, относятся экологические (агроэкологические) риски, которые в настоящее время служат приоритетными обобщенными параметрами техногенного воздействия на агроэкосистемы (37-39). Количественные показатели могут быть стандартизованы посредством выработки нормативов по риску (приемлемых рисков) и в дальнейшем использованы для всесторонней оценки состояния компонентов агроэкосистем (40-42). Используемые в настоящее время показатели ПДК/ОДК (предельно допустимая концентрация/ориентировочно допустимая концентрация) имеют определенные недостатки: в них не разделяются вклады природных и техногенных компонентов, не учитываются природно-климатические и геохимические особенности регионов (43-45). 
В наших ранних исследованиях была разработана методология оценки рисков, возникающих вследствие радиационных аварий, для аграрных экосистем. Предложенные подходы использованы при расчете агроэкологического риска для сельскохозяйственных культур при радиоактивном загрязнении ${ }^{137} \mathrm{Cs}$, связанным с выбросом в атмосферу радионуклидов при аварии на радиационно-опасном объекте (9). В то же время следует отметить, что существующее многообразие методик для оценки агроэкологических рисков затрудняет сопоставление их результатов и, как следствие, получение достоверных данных о негативном влиянии техногенных факторов на компоненты агроэкосистем (46-48). Кроме того, оценки рисков при техногенных воздействиях выполняются, как правило, ситуативно для конкретного анализируемого случая и с использованием частных методов, применимых для определенного фактора (агента) в конкретных условиях и объекта его воздействия (10).

Целью представленного теоретического исследования стала разработка единой методологии оценки агроэкологических рисков, обусловленных последствиями техногенного загрязнения.

Этапы оценки агроэкологических рисков, вызван ных последствия ми техногенного загрязнения. Реализация принципов ограничения и прогнозирования негативного воздействия техногенных факторов разной природы на компоненты агроэкосистем должна основываться на оценке рисков, базирующейся на количественных или качественных характеристиках - обобщенных критериях. Это критерии, позволяющие при известной степени техногенного загрязнения агроэкосистемы оценить вероятность 50 \% гибели сельскохозяйственных растений и объемы снижения урожая (49-51).

Оценка агроэкологических рисков для сельского хозяйства в условиях техногенного загрязнения обычно включает четыре этапа (52-54). Рассмотрим их с точки зрения поставленной нами задачи по унификации методологии анализа рисков независимо от характера техногенного загрязнения.

I этап. Идентификация опасности. На этом этапе проводят сбор и обобщение доступной информации с целью определения источников загрязнения и их природы (радиационные, химические, биологические), а также характеристика степени воздействия техногенных факторов. Особое внимание необходимо уделять компонентам аграрной экосистемы, в наибольшей степени подверженным влиянию техногенных факторов, - «критическим» компонентам $(55,56)$, критериями выбора которых служат чувствительность к тому или иному негативному фактору, а также степень его воздействия. Чувствительность растений - это их способность реагировать на внешнее раздражение, которая проявляется в разных формах.

\section{1. Доза $\gamma$-облучения, приводящая к снижению урожая различных сельскохозяй-} ственных культур на 50 \% (57)

\begin{tabular}{lc}
\hline \multicolumn{1}{c}{ Культура } & Поглощенная доза облучения, Гр \\
\hline Рожь озимая, бобы конские & $5-8$ \\
Пшеница озимая и яровая, ячмень, овес, кукуруза, горох, соя & $10-20$ \\
Подсолнечник, рапс & $20-30$ \\
Гречиха, просо, рис & $30-50$ \\
Хлопчатник, помидоры & $50-80$ \\
Капуста & $80-120$ \\
Картофель & $120-150$ \\
Свекла сахарная и столовая & $180-220$ \\
Морковь & $250-300$ \\
Лен & $300-400$ \\
\hline
\end{tabular}

При выборе приоритетного загрязнителя или их группы для количественной оценки агроэкологического риска необходимо ориентироваться 
на критерии, характеризующие содержание загрязнителей в «критических» компонентах агроэкосистемы, токсические свойства веществ, способность к миграции, вероятность проявления негативного эффекта, обусловленного различными вариантами воздействия. Следует учитывать все факторы, действующие в системе, - физические, химические и иные, в частности миграцию поллютанта, его трансформацию, продолжительность воздействия (58-60). При идентификации техногенных факторов риска для компонентов аграрной экосистемы надо основываться на проектной документации источника загрязнения, результатах экологического мониторинга или специальных исследований.

На этапе идентификации опасности формируется предварительный сценарий влияния техногенного фактора на «критические» компоненты агроэкосистемы, который содержит информацию о физико-химических свойствах вещества и о том, каким образом, с какой интенсивностью и продолжительностью оно воздействует на организм. Для каждого выявленного техногенного фактора устанавливается перечень показателей (эффектов), отражающих нарушение функционирования компонентов агроэкосистемы. Источниками данных о негативных эффектах могут быть достоверные результаты, опубликованные в научной литературе. Широко используются такие показатели, как интенсивность прироста биомассы (продуктивность) и биомасса растительности, сформировавшаяся к определенному моменту времени (урожайность). При радиационном воздействии на сельскохозяйственные культуры они оценены наиболее точно (табл. 1, 2). При невысокой степени техногенного воздействия значимы показатели, наблюдаемые на более низких уровнях биологической организации (организменном, клеточном и субклеточном) $(61,62)$.

2. Вероятные потери урожая зерновых (\%) при воздействии ионизирующего излучения на разных фазах развития растений (57)

\begin{tabular}{|c|c|c|c|c|c|c|c|}
\hline \multirow{2}{*}{ Фаза развития растений } & \multicolumn{7}{|c|}{ Суммарные дозы $\gamma$ - и $\beta$ - излучения, Гр } \\
\hline & 5 & 10 & 20 & 30 & 50 & 100 & 200 \\
\hline \multicolumn{8}{|c|}{ Рожь ози м ая } \\
\hline Кущение & 5 & 15 & 40 & 70 & 95 & 100 & 100 \\
\hline Выход в трубку & 25 & 80 & 95 & 100 & 100 & 100 & 100 \\
\hline Колошение-цветение & 15 & 40 & 75 & 95 & 100 & 100 & 100 \\
\hline \multirow[t]{2}{*}{ Молочная спелость } & 5 & 6 & 8 & 10 & 15 & 30 & 50 \\
\hline & & я ро в а я & и ози & о в е & Я ч м е & & \\
\hline Кущение & 5 & 8 & 27 & 50 & 95 & 100 & 100 \\
\hline Выход в трубку & 9 & 20 & 50 & 75 & 90 & 100 & 100 \\
\hline Колошение-цветение & 7 & 15 & 35 & 50 & 75 & 95 & 100 \\
\hline Молочная спелость & 4 & 5 & 7 & 10 & 15 & 30 & 50 \\
\hline \multicolumn{8}{|c|}{ Кукуруза } \\
\hline 6-8 листьев & 15 & 25 & 40 & 55 & 85 & 100 & 100 \\
\hline Выметывание метелки & 30 & 45 & 55 & 70 & 95 & 100 & 100 \\
\hline Молочная спелость & 4 & 10 & 20 & 30 & 40 & 60 & 80 \\
\hline
\end{tabular}

Интегральный риск для компонентов аграрной экосистемы необходимо оценивать на основе обобщенной информации, включающей данные о воздействии каждого фактора риска. Уже на этом этапе могут быть приняты предварительные решения по управлению агроэкологическим риском, включая прекращение дальнейшего анализа ввиду незначительной опасности или достаточности полученных первичных оценок, проведение более детального анализа опасностей и оценки риска, разработку предварительных рекомендаций по уменьшению опасностей (9).

II этап. Оценка воздействия. Включает измерение и (или) расчет интенсивности и продолжительности, а также путей воздействия техногенных факторов на компоненты аграрной экосистемы. Под интенсивностью радиационного фактора подразумевается доза облучения биологических 
объектов, для химического фактора это концентрация или доза химического вещества, для биологического фактора - количество биологических агентов, поступивших в организм в единицу времени. Источником информации об интенсивности техногенного фактора служат накопленные научные данные, полученные как за предшествующий период, так и в результате проведенных экспериментов, а также данные из опубликованных научных работ и отчетов. Одним из основных источников техногенного воздействия на аграрные экосистемы следует считать атмосферный путь поступления радионуклидов, химических веществ, биологических агентов. При оценке экспозиционных нагрузок продолжительность радиационного воздействия менее 2 нед идентифицируется как острая, до 7 лет - подострая, более 7 лет - хроническая (10).

Оценка влияния техногенных факторов на компоненты аграрной экосистемы, выполняется на основании последовательности действий, к которым относят: анализ обобщенной информации об уровнях воздействия техногенных факторов, включая значения рассматриваемых эффектов, оказываемых на компоненты аграрной экосистемы при разной степени техногенного воздействия; определение метеорологических параметров модели поведения примесей в атмосфере для конкретных условий выброса (класс устойчивости атмосферы, скорость ветра на высоте выброса, величина аэродинамической шероховатости подстилающей поверхности в соответствии с МУ 2.6.5.010-2016) (63); оценку величины осаждения примесей на земную поверхность в зависимости от особенностей техногенного загрязнения; оценка загрязнения приоритетными веществами надземной фитомассы сельскохозяйственных растений и почвы; расчет или измерение степени воздействия приоритетных веществ на сельскохозяйственные растения.

Результатом второго этапа становится количественное описание интенсивности, частоты и характера воздействия на компоненты агроэкосистемы техногенных факторов.

III этап. Оиенка зависимости «доза-эффект». Отражает количественную связь между степенью воздействия техногенных факторов и вероятностью возникновения негативных эффектов в компонентах аграрной экосистемы с учетом тяжести их последствий (9).

Оценка зависимости «доза-эффект» базируется на накопленных научных данных, математических моделях и критериях агроэкологической безопасности компонентов агроэкосистемы. Эта информация должна характеризовать зависимость негативных эффектов на компоненты аграрной экосистемы от конкретной величины воздействия техногенных факторов. Выбор степени воздействия факторов риска на компоненты аграрной экосистемы следует проводить с учетом негативных эффектов, возникающих при минимальном воздействии, а также при его различной временной продолжительности (острая, подострая, хроническая). Отклик биотической компоненты агроэкосистемы выше приемлемого экологического риска характеризуется показателем полулетальных доз (ЛД50), обоснованным по критерию выживаемости компонентов аграрной экосистемы или предельно допустимой концентрацией (ПДК) $(9,10)$.

Результатом выполнения этого этапа становятся модели, которые описывают зависимость «доза-эффект», содержат количественно определенные параметры и характеристику «критических» компонентов агроэкосистемы и позволяют оценить вероятность негативных эффектов от воздействия установленных ранее техногенных факторов.

Выбор методов, положенных в основу моделей оценки агроэкологических рисков, определяется в первую очередь степенью информационного 
обеспечения показателей (совокупность критериев оценки риска, уровни техногенного воздействия). При оценке риска наиболее часто применяются детерминистский, вероятностные и интегральный вероятностный методы (9). При применении детерминистского метода выполняется оценка индексов риска, представляющих собой отношения дозовой нагрузки к величине критерия риска (уровня приемлемого экологического риска). Достоинство метода - относительная простота реализации и небольшой объем входной информации (требуется наличие двух показателей). К недостаткам можно отнести отсутствие учета неопределенностей показателей и, как следствие, приблизительность оценок (4). Вероятностные методы бывают 1-го и 2-го типа. В рамках вероятностного метода 1-го типа в качестве критерия риска используется точечная оценка. Вероятностный метод 2-го типа целесообразно применять в том случае, когда идентификация распределения действующего техногенного фактора затруднительна вследствие недостатка данных или необходимости оперативной оценки (4, 10). При применении интегрального вероятностного метода учитываются неопределенности, присущие рассматриваемому объекту и характеристикам окружающей среды, которые определяют интенсивность воздействия техногенного фактора (9).

IV этап. Характеристика риска. Включает анализ степени надежности данных об опасности техногенных факторов, полученных на предшествующих этапах. На основе рассчитанных количественных показателей зависимости «доза-эффект» и сравнения полученных результатов с данными аналогичных исследований дается заключение о степени и вероятности экологического риска для «критической» компоненты или аграрной экосистемы в целом. На этом этапе осушествляется классификация риска и оценка его соответствия приемлемому экологическому уровню (использование величин ПДК и ЛД50) $(9,10)$.

Анализ источников неопределенности - это неотъемлемая часть оценки агроэкологических рисков, которая существенно повышает надежность и достоверность полученных результатов. Неопределенность может быть связана с недостатком информации о проблеме в целом; отсутствием или недостоверностью данных, необходимых для определения уровня риска; недостатком научно-теоретических знаний для формирования соответствующей концептуальной или расчетной модели; недостатком знаний об истинном характере статистического распределения данных (9).

Возможные неопределенности этапа идентификации опасности включают недостаточное количество сведений об исследуемых компонентах аграрной экосистемы; некорректные характеристики установленных факторов агроэкологического риска; отсутствие данных о негативных эффектах для компонентов аграрной экосистемы; неверное формирование исходной выборки данных. К основным источникам неопределенности при «оценке воздействия» относятся некорректность выбора моделей воздействия или вводимых параметров; ошибки выбора путей воздействия. Источниками неопределенности на этапе оценки зависимости «доза-эффект» могут быть ошибки в определении «критических» компонент аграрной экосистемы; степень достоверности негативных эффектов (9).

Результатом оценки неопределенностей при расчете агроэкологических рисков могут быть принятие решений без ограничений (первый уровень); принятие решений, направленных на минимизацию риска, или конкретных решений управления риском (второй уровень); данные, имеющие оценочный характер и используемые для моделирования ситуации (третий уровень) $(9,10)$. 
Результаты выполнения всех этапов становятся основой для принятия решения по управлению агроэкологическими рисками, обусловленными техногенным загрязнение.

Алгоритм оценки агроэкологических рисков, обусловленных последствиями техногенного загрязнения . Обобщенный алгоритм оценки агроэкологических рисков можно представить в следующем виде.

Первый этап - анализ базы данных (БД), формирование выборок из БД, которые включают количественные значения параметров, характеризующих рассматриваемые негативные эффекты при различной степени техногенного воздействия.

На втором этапе определяются метеорологические параметры модели поведения загрязнителей в атмосфере для конкретных условий выброса (класс устойчивости атмосферы, скорость ветра на высоте выброса, величина аэродинамической шероховатости подстилающей поверхности) в соответствии с МУ 2.6.5.010-2016 (63). Класс устойчивости атмосферы определяется по F. Pasquill (64).

Третий этап включает определение величины осаждения загрязняющих веществ на земную поверхность расчетными или экспериментальными методами в зависимости от особенностей техногенного воздействия. Следует отметить, что в настоящее время наиболее полно проработана оценка интенсивности поступления на земную поверхность радиоактивных и химических веществ, обусловленных техногенным загрязнением $(65,66)$.

Плотность выпадения радиоактивных или химических веществ на земную поверхность определяется формулой:

$$
\operatorname{Asn}_{n}(\mathrm{x})=\mathrm{Q} \cdot\left(\mathrm{V}_{\mathrm{g}} \cdot \mathrm{G}(\mathrm{x})\right),
$$

где $\mathrm{Q}$ - интегральный выброс радиоактивных или химических веществ, г или Бк; $\mathrm{V}_{\mathrm{g}}$ - скорость гравитационного осаждения радиоактивных или химических веществ, м/c; G(x) - фактор метеорологического разбавления на удалении х метров от источника выброса, с/м³ (65).

Параметр метеорологического разбавления на различном удалении х от источника выброса рассчитывается на уровне подстилающей поверхности $(\mathrm{z}=0)$ на оси следа выпадений $(\mathrm{y}=0)(65)$ :

$$
\mathrm{G}(\mathrm{x})=\frac{\mathrm{f}_{\mathrm{p}}(\mathrm{x}) \cdot \mathrm{f}_{\mathrm{oc}}(\mathrm{x}) \cdot \mathrm{f}_{\mathrm{B}}(\mathrm{x})}{\pi \cdot \sigma_{\mathrm{y}}(\mathrm{x}) \cdot \sigma_{\mathrm{z}}(\mathrm{x}) \cdot \mathrm{U}} \cdot \exp ^{\left(-\frac{\mathrm{H}_{\mathrm{g}}^{2}}{2 \cdot \sigma_{\mathrm{z}}(\mathrm{x})}\right),}
$$

где $\mathrm{x}$ - расстояние до источника выброса, м; U - скорость ветра на высоте выброса, м/с; Нg - высота выброса над землей, м; бz, бу - стандартные отклонения распределения примеси загрязняющих веществ в облаке выброса в направлении соответствующих координатных осей, м (67); fр или $\mathrm{f}_{\mathrm{Tp}}, \mathrm{f}_{\mathrm{c}}, \mathrm{f}_{\mathrm{B}}$ - поправки на распад или химическую трансформацию, осаждение и вымывание загрязнителей из атмосферы осадками.

Выражение для поправки на распад радионуклида или химическую трансформацию токсиканта имеет вид:

$$
\mathrm{f}_{\mathrm{p}}(\mathrm{x})=\exp (-\lambda \cdot \mathrm{x} / \mathrm{u})
$$

где $\lambda-$ постоянная радиоактивного распада для конкретного радионуклида или постоянная химической трансформации, $1 / \mathrm{c} ; \mathrm{x} / \mathrm{u}-$ время движения облака к точке с удалением х от места выброса (65).

Поправка на гравитационное осаждение рассчитывается по формуле:

$$
\mathrm{f}_{\mathrm{oc}}(\mathrm{x})=\exp \left[-\sqrt{\frac{2}{\pi}} \cdot \frac{\mathrm{v}_{\mathrm{g}}}{\mathrm{u}} \int_{0}^{\mathrm{x}}\left(\frac{1}{\sigma_{\mathrm{z}}(\mathrm{x}) \cdot \exp \left(0.5 \cdot \mathrm{h}^{2} \cdot \sigma_{\mathrm{z}}^{-2}(\mathrm{x})\right.}\right) \mathrm{dx}\right],
$$


где $\mathrm{vg}-$ скорость гравитационного осаждения, м/с (для аэрозолей $-0,001$, для элементарного йода $-0,02$, для органического йода $-0,0005$, для инертных газов - 0 м/с) (65).

Поправка на вымывание химических токсикантов или радиоактивных веществ из атмосферы имеет вид:

$$
\mathrm{f}_{\mathrm{B}}(\mathrm{x})=\exp (-\Lambda \cdot \mathrm{x} / \mathrm{u})
$$

где $\Lambda$ - среднегодовая постоянная выведения примеси из атмосферы осадками, усредненная за год с учетом типа и продолжительности осадков в течение года, 1/с (65).

На четвертом этапе определяют содержание загрязняющих веществ в компонентах агроэкосистемы расчетными или экспериментальными методами. Расчет концентрации радионуклидов (Бк) или химических токсикантов (г), в надземной фитомассе сельскохозяйственных растений агроэкосистемы на любые сутки после выброса q(t) проводится по следующей предлагаемой формуле:

$$
\mathrm{q}(\mathrm{t})=\frac{\mathrm{K}_{3}\left(\mathrm{t}_{\mathrm{o}}\right) \cdot \exp ^{\left[-\left(\lambda+\lambda_{\text {эк }}\right) \cdot\left(\mathrm{t}-\mathrm{t}_{\mathrm{o}}\right)\right]}}{\mathrm{a} \cdot\left(\mathrm{t}-\mathrm{t}_{\text {нв }}\right) \cdot 4} \cdot \mathrm{As}_{\mathrm{n}}(\mathrm{x}),
$$

где $\lambda$ - константа радиоактивного распада для радионуклидов или химического преобразования токсикантов, $1 /$ сут; $\lambda$ эк - константа скорости потерь радионуклидов или химических токсикантов из надземной фитомассы, 1/сут; to - число суток, прошедших с начала года на момент выпадений; $\mathrm{t}$ - число суток, прошедших с начала года, для которых определяются основные характеристики компонент агроэкосистемы (высота и биомасса растений, концентрация загрязняющих веществ в основных компонентах, дозовые характеристики в надземной фитомассе сельскохозяйственных растений); 4 - коэффициент пересчета от воздушно-сухой массы к нативной.

Коэффициент первоначального задерживания надземной фитомассой растений радионуклидов или химических токсикантов предлагается рассчитывать, как

$$
\mathrm{K}_{3}\left(\mathrm{t}_{0}\right)=1-\exp ^{\left(-\mu \cdot \rho\left(\mathrm{t}_{0}\right)\right)}
$$

где $\mu$ - эмпирическая константа, отражающая задерживание радионуклидов или химических токсикантов растительным покровом $\left(2,8 \mathrm{~m}^{2}\right.$ кг воздушно-сухой массы), $\rho\left(\mathrm{t}_{0}\right)$ - запас надземной биомассы в момент выпадений $\mathrm{t} 0, \mathrm{Kг} \cdot \mathrm{M}^{2}$.

Запас надземной фитомассы растений в момент выпадений определяется по формуле (67):

$$
\rho\left(\mathrm{t}_{0}\right)=\mathrm{a} \cdot\left(\mathrm{t}_{\mathrm{o}}-\mathrm{t}_{\text {н.в. }}\right),
$$

где а - скорость прироста биомассы на единице площади посева, кг/(м • сут)

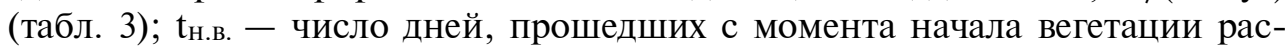

\begin{tabular}{|c|c|c|c|}
\hline Культура & $\begin{array}{l}\text { Календарный срок } \\
\text { начала вегетации }\end{array}$ & $\begin{array}{l}\text { Время с начала } \\
\text { вегетации (tн.в.), сут }\end{array}$ & $\begin{array}{l}\text { Скорость прироста } \\
\text { биомассы, кг/(м².сут) }\end{array}$ \\
\hline Пшеница яровая & 15 мая & 135 & $6 \times 10^{-3}$ \\
\hline Рожь яровая & 15 мая & 135 & $6 \times 10^{-3}$ \\
\hline Ячмень & 15 мая & 135 & $3 \times 10^{-3}$ \\
\hline Овес & 15 мая & 135 & $3 \times 10^{-3}$ \\
\hline Картофель & 25 мая & 145 & $9 \times 10^{-4}$ \\
\hline Свекла & 5 июня & 155 & $6,4 \times 10^{-4}$ \\
\hline Капуста & 20 мая & 140 & $6,4 \times 10^{-4}$ \\
\hline Трава сенокосов & 15 апреля & 105 & $6,4 \times 10^{-4}$ \\
\hline
\end{tabular}
сматриваемого вида сельскохозяйственных растений (см. табл. 3).

3. Характеристики вегетационного периода и скорости прироста биомассы некоторых видов сельскохозяйственных растений (10)

На пятом этапе согласно рассматриваемому алгоритму оценки аг- 
роэкологических рисков выполняют расчет или измерение степени воздействия загрязняющих веществ на компоненты агроэкосистем. В случае выброса химических веществ, рассчитанную концентрацию токсикантов [6] следует рассматривать в качестве исходной для определения степени воздействия загрязнителей на сельскохозяйственные растения. Для оценки воздействия радионуклидов на сельскохозяйственные растения нужно рассматривать два основных источника облучения $(68,69)-$ бесконечный источник конечной толщины, равный высоте растений с равномерным распределением активности (состоит из загрязненных радионуклидами растений и атмосферного воздуха, заполняющего промежутки ними, что принимается за воздушно-растительную среду) и бесконечный источник излуче-

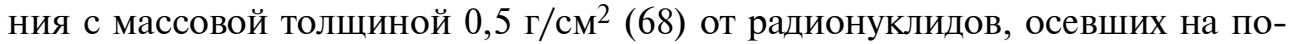
верхность почвы в силу неполного задерживания частиц выпадений надземной фитомассой.

Более подробно методы оценки воздействия радионуклидов на сельскохозяйственные растения от различных источников поступления описаны в работе Т.В. Переволоцкой с соавт. (9).

В заключение отметим, что в условиях развитие мировой промышленности и индустриальных систем агропроизводства вероятность комплексных техногенных загрязнений $(11,14)$, в том числе создающих потенциальную опасность для здоровья человека $(15,18,20)$, объективно повышается. Для контроля таких угроз недостаточно располагать набором методов, пригодных для анализа частных случаев техногенного воздействия. Предложенная нами методология устанавливает критерии и подходы, которые позволяют оценить агроэкологические риски, вызванные техногенными загрязнениями независимо от их природы $(70,71)$. Описанные методы создания моделей, необходимых для оценки агроэкологических рисков, применимы при решении широкого круга экологических проблем, включая охрану здоровья человека $(72,73)$, и могут быть основой рекомендаций по управлению техногенными рисками в агропромышленном комплексе в связи с природоохранными задачами, контролем и прогнозом загрязнения окружающей среды.

Таким образом, нами разработана единая методология оценки рисков техногенных загрязнениях разной природы для аграрных экосистем. Ее основу составляют принципы и критерии минимизации угроз и обеспечения безопасности агроэкосистем в условиях техногенеза. В качестве аналитического инструмента используется математическое моделирование. В методологии определены подходы и критерии оценки агроэкологических рисков. Предложена методическая база, которая позволяет исследовать динамику дозозависимых эффектов различных факторов в отношении индивидуальных компонентов системы и на основе полученных результатов формировать управленческие решения по минимизации агроэкологических рисков.

\section{ЛИ Т Е РАТ У РА}

1. Каткова М.Н., Иваницкая М.В. Оценка химического риска для населения, проживающего в зоне влияния радиационного объекта (на примере п. Новогорный Челябинской области). Радиация и риск, 2008, 17(4): 67-78.

2. Franco-Uría A., López-Mateo C., Roca E., Fernández-Marcos M.L. Source identification of heavy metals in pastureland by multivariate analysis in NW Spain. Journal of Hazardous Materials, 2009, 165(1-3): 1008-1015 (doi: 10.1016/j.jhazmat.2008.10.118).

3. Rajaganapathy V., Xavier F., Sreekumar D., Mandal P.K. Heavy metal contamination in soil, water and fodder and their presence in livestock and products: a review. Journal of Environmental 
Science and Technology, 2011, 4(3): 234-249 (doi: 10.3923/jest.2011.234.249).

4. Ильязов Р.Г., Алексахин Р.М., Фисинин В.И., Смирнов А.М., Гусманов У.Г. Методология исследований и экспериментов в агроэкосфере при различных типах техногенеза. Сельскохозяйственная биология, 2010, 2: 3-17.

5. Manzoor S., Shah M.H., Shaheen N., Khalique A., Jaffar M. Multivariate analysis of trace metals in textile effluents in relation to soil and groundwaters. Journal of Hazardous Materials, 2006, 137(1): 31-37 (doi: 10.1016/j.jhazmat.2006.01.077).

6. Музалевскиий А.А., Карлин Л.Н. Экологические риски: теория и практика. СПб, 2011.

7. Башкин В.Н. Экологические риски: расчет, управление, страхование. М., 2007.

8. Dalezios N.R., Blanta A., Spyropoulos N.V., Tarquis A.M. Risk identification of agricultural drought for sustainable agroecosystems. Natural Hazards and Earth System Science, 2014, 14(9): 2435-2448 (doi: 10.5194/nhess-14-2435-2014).

9. Переволоцкая Т.В., Панов А.В. Методология оценки агроэкологических рисков, обусловленных последствиями радиационных аварий. Радиащия и риск, 2018, 27(4): 119-132 (doi: 10.21870/0131-3878-2018-27-4-119-132).

10. Спиридонов С.И., Санжарова Н.И., Тетенькин В.Л., Гераськин С.А., Панов А.В., Соломатин В.М., Епифанова И.Э., Карпенко Е.И. Методология оценки риска воздействия техногенных факторов различной природы на агроэкосистемы. Обнинск, 2007.

11. Li Z., Ma Z., van der Kuijp T.J., Yuan Z., Huang L. A review of soil heavy metal pollution from mines in China: pollution and health risk assessment. Science of the Total Environment, 2014, 468469: 843-853 (doi: 10.1016/j.scitotenv.2013.08.090).

12. Fraga C.G. Relevance, essentiality and toxicity of trace elements in human health. Molecular Aspects of Medicine, 2005, 26(4-5): 235-244 (doi: 10.1016/j.mam.2005.07.013).

13. Vries W., Römkens P.F.A.M., Schütze G. Critical soil concentrations of cadmium, lead, and mercury in view of health effects on humans and animals. In: Reviews of environmental contamination and toxicology, vol. 191. Springer, New York, NY, 2007: 91-130 (doi: 10.1007/978-0-38769163-3 4).

14. Kim J., Lee Y., Yang M. Environmental exposure to lead ( $\mathrm{Pb})$ and variations in its susceptibility. Journal of Environmental Science and Health, Part C: Environmental Carcinogenesis and Ecotoxicology Reviews, 2014, 32(2): 159-185 (doi: 10.1080/10590501.2014.907461).

15. Bortey-Sam N., Nakayama S.M.M., Ikenaka Y., Akoto O., Baidoo E., Yohannes Y.B., Mizukawa H., Ishizuka M. Human health risks from metals and metalloid via consumption of food animals near gold mines in Tarkwa, Ghana: estimation of the daily intakes and target hazard quotients (THQs). Ecotoxicology and Environmental Safety, 2015, 111: 160-167 (doi: 10.1016/j.ecoenv.2014.09.008).

16. Miranda M., López-Alonso M., Castillo C., Hernández J., Benedito J.L. Effects of moderate pollution on toxic and trace metal levels in calves from a polluted area of northern Spain. Environment International, 2005, 31(4): 543-458 (doi: 10.1016/j.envint.2004.09.025).

17. Cai Q., Long M.L., Zhu M., Zhou Q.Z., Zhang L., Liu J. Food chain transfer of cadmium and lead to cattle in a lead-zinc smelter in Guizhou, China. Environmental Pollution, 2009, 157(11): 3078-3082 (doi: 10.1016/j.envpol.2009.05.048).

18. Miranda M., Benedito J.L., Blanco-Penedo I., López-Lamas C., Merino A., López-Alonso M. Metal accumulation in cattle raised in a serpentine-soil area: relationship between metal concentrations in soil, forage and animal tissues. Journal of Trace Elements in Medicine and Biology, 2009, 23(3): 231-238 (doi: 10.1016/j.jtemb.2009.03.004).

19. Hänsch R., Mendel R.R. Physiological functions of mineral micronutrients $(\mathrm{Cu}, \mathrm{Zn}, \mathrm{Mn}, \mathrm{Fe}, \mathrm{Ni}$, Mo, B, Cl). Current Opinion in Plant Biology, 2009, 12(3): 259-266 (doi: 10.1016/j.pbi.2009.05.006).

20. Skalny A.V., Salnikova E.V., Burtseva T.I., Skalnaya M.G., Tinkov A.A. Zinc, copper, cadmium, and lead levels in cattle tissues in relation to different metal levels in ground water and soil. Environmental Science and Pollution Research, 2019, 26: 559-569 (doi: 10.1007/s11356-0183654-y).

21. Sánchez-Pardo B., Fernández-Pascual M., Zornoza P. Copper microlocalisation, ultrastructural alterations and antioxidant responses in the nodules of white lupin and soybean plants grown under conditions of copper excess. Environmental and Experimental Botany, 2012, 84: 52-60 (doi: 10.1016/j.envexpbot.2012.04.017).

22. Цыгвинцев П.Н., Гончарова Л.И., Манин К.В., Рачкова В.М. Определение оптимального содержания меди в почвах разного типа на основании динамической модели ее накопления в надземной биомассе и корнях растений (на примере ячменя Hordeum vulgare L.). Сельскохозяйственная биология, 2018, 53(3): 570-577 (doi: 10.15389/agrobiology.2018.3.570rus).

23. Küpper H., Götz B., Mijovilovich A., Küpper F.C., Meyer-Klaucke W. Complexation and toxicity of copper in higher plants. I. Characterization of copper accumulation, speciation, and toxicity in Crassula helmsii as a new copper accumulator. Plant Physiology, 2009, 151(2): $702-714$ (doi: 10.1104/pp.109.139717).

24. Wang X., Ma Y., Hua L., McLaughlin M.J. Identification of hydroxyl copper toxicity to barley (Hordeum vulgare) root elongation in solution culture. Environmental Toxicology and Chemistry, 2009, 28(3): 662-667 (doi: 10.1897/07-641.1). 
25. Barman S.C., Sahu R.K., Bhargava S. K., Chaterjee C. Distribution of heavy metals in wheat, mustard, and weed grown in field irrigated with industrial effluents. Bulletin of the Environmental Contamination and Toxicology, 2000, 64: 489-496 (doi: 10.1007/s001280000030).

26. Vodyanitskii Yu.N., Plekhanova I.O., Prokopovich E.V., Savichev A.T. Soil contamination with emissions of non-ferrous metallurgical plants. Eurasion Soil Science, 2011, 44: 217-226 (doi: 10.1134/S1064229311020177).

27. Vodyanitskii Yu.N. Contamination of soils with heavy metals and metalloids and its ecological hazards (analytic review). Eurasion Soil Science, 2013, 46: 793-801 (doi: 10.1134/S1064229313050153).

28. Antle J.M., Basso B., Conant R.T., Godfray H.C.J., Jones J.W., Herrero M., Howitt R.E., Keating B.A., Munoz-Carpena R., Rosenzweig C., Tittonell P., Wheeler T.R. Towards a new generation of agricultural system data, models and knowledge products: design and improvement. $A g$ ricultural Systems, 2017, 155: 255-268 (doi: 10.1016/j.agsy.2016.10.002).

29. Анисимов В.С., Анисимова Л.Н., Фригидова Л.М., Санжарова Н.И., Фригидов Р.А., Дикарев Д.В., Корнеев Ю.Н. Подвижность цинка и накопление его в корнеплодах редиса в зависимости от типа почвы. Вестник Российской сельскохозяйственной науки, 2016, 4: 14-17.

30. Ульяненко Л.Н., Филипас А.С., Лой Н.Н., Степанчикова Н.С., Круглов С.В. Влияние загрязнения кадмием дерново-подзолистой почвы на рост и развитие растений ячменя. Агрохимия, 2009, 6: 56-60.

31. Lequeux H., Hermans C., Lutts S., Verbruggen N. Response to copper excess in Arabidopsis thaliana: impact on the root system architecture, hormone distribution, lignin accumulation and mineral profile. Plant Physiology and Biochemistry, 2010, 48(8): 673-682 (doi: 10.1016/j.plaphy.2010.05.005).

32. Talukdar D. Studies on antioxidant enzymes in Canna Indica plant under copper stress. Journal of Environmental Biology, 2013, 34(1): 93-98.

33. Fidalgo F., Azenha M., Silva A.F., de Sousa A., Santiago A., Ferraz P., Teixeira J. Copperinduced stress in Solanum nigrum L. and antioxidant defense system responses. Food and Energy Security, 2013, 2(1): 70-80 (doi: 10.1002/fes3.20).

34. Demková L., Árvay J., Bobul'ská L., Tomáš J., Stanovič R., Lošák T., Harangozo L., Vollmannová A., Bystrická J., Musilová J. Jobbágy J. Accumulation and environmental risk assessment of heavy metals in soil and plants of four different ecosystems in a former polymetallic ore mining and smelting area (Slovakia). Journal of Environmental Science and Health Part A Toxic/Hazardous Substances \& Environmental Engineering, 2017, 52(5): 479-490 (doi: 10.1080/10934529.2016.1274169).

35. Kisku G.C., Barman S.C., Bhargava S.K. Contamination of soil and plants with potentially toxic elements irrigated with mixed industrial effluent and its impact on the environment. Water, Air, and Soil Pollution, 2000, 120(1-2): 121-137 (doi: 10.1023/A:1005202304584).

36. Rowe E.C., Wamelink G.W.W., Smart S.M., Butler A., Henrys P.A., van Dobben H.F., Reinds G.J., Evans C.D., Kros J., de Vries W. Field survey-based models for exploring nitrogen and acidity effects on plant species diversity and assessing long-term critical loads. In: Critical loads and dynamic risk assessments. Environmental pollution, vol. 25. Springer, Dordrecht, 2015: 297-326 (doi: 10.1007/978-94-017-9508-1_11).

37. U.S. EPA. Concepts, methods, and data sources for cumulative health risk assessment of multiple chemicals, exposures and effects: A resource document (Final report, 2008). U.S. Environmental Protection Agency, Washington, DC, EPA/600/R-06/013F, 2007.

38. Munns J.W.R., Kroes R., Veith G.D., Suter II G.W., Damstra T., Waters M.D. Approaches for integrated risk assessment. Human and ecological risk assessment: An International Journal, 2003, 9(1): 267-272 (doi: 10.1080/713609863).

39. Munns W.R. Jr., Poulsen V., Gala W.R., Marshall S.J., Rea A.W., Sorensen M.T., von Stackelberg K. Ecosystem services in risk assessment and management. Integrated Environmental Assessment and Management, 2017, 13(1): 62-73 (doi: 10.1002/ieam.1835).

40. Franklin J., Regan H.M., Syphard A.D. Linking spatially explicit species distribution and population models to plan for the persistence of plant species under global change for the persistence of plant species under global change. Environmental Conservation, 2014, 41(2): 97-109 (doi: 10.1017/S0376892913000453).

41. Stern B.R. Essentiality and toxicity in copper health risk assessment: overview, update and regulatory considerations. Journal of Toxicology and Environmental Health, Part A, 2010, 73(2-3): 114127 (doi: 10.1080/15287390903337100).

42. White P.J., Brown P.H. Plant nutrition for sustainable development and global health. Annals of Botany, 2010, 105(7): 1073-1080 (doi: 10.1093/aob/mcq085).

43. Цыгвинцев П.Н., Гончарова Л.И., Рачкова В.М. Ответная реакция ячменя в онтогенезе на загрязнение почв медью. Успехи современного естествознания, 2018, 11(2): 305-310.

44. Буданцев П.Б., Уваров Л.А., Цыплаков С.Е. Исследование содержания тяжелых металлов в почвах зоны техногенеза. Агрохимия, 2011, 4: 74-81.

45. Гладков Е.А. Оценка комплексной фитотоксичности тяжелых металлов и определение ориентировочно допустимых концентраций для цинка и меди. Сельскохозяйственная биология, 2010, 45(6): 94-99. 
46. Shao C., Yang J., Tian X., Ju M., Huang L. Integrated environmental risk assessment and wholeprocess management system in chemical industry parks. International Journal of Environmental Research and Public Health, 2013, 10(4): 1609-1630 (doi: 10.3390/ijerph10041609).

47. Chen J., Shafi M., Li S., Wang Y., Wu J., Peng Z.Y.D., Yan W., Liu D. Copper induced oxidative stresses, antioxidant responses and phytoremediation potential of Moso bamboo (Phyllostachys pubescens). Scientific Reports, 2015, 5: 13554 (doi: 10.1038/srep13554).

48. Bizzo A.L.T., Intorne A.C., Gomes P.H., Suzuki M.S., dos Santos Esteves B. Short-term physiological responses to copper stress in Salvinia auriculata Aubl. Acta Limnologica Brasiliensia, 2014, 26(3): 268-277 (doi: 10.1590/S2179-975X2014000300006).

49. Гончарова Л.И., Манин К.В., Рачкова В.М. Влияние загрязнения почв медью на фотосинтетическую активность и окислительно-восстановительный гомеостаз растений кормовых бобов. Агрохимия, 2011, 6: 61-67.

50. Фригидов Р.А., Анисимов В.С., Фригидова Л.М., Гераськин С.А., Анисимова Л.Н., Корнеев Ю.Н., Санжарова Н.И. Влияние концентрации Zn в почвах на динамику накопления биомассы и металла растениями ячменя. Агрохимия, 2014, 12: 42-54.

51. Цыгвинцев П.Н., Гончарова Л.И., Санжарова Н.И., Рачкова В.М. Оценка оптимальных и критических уровней содержания меди в почвах для ячменя. Агрохимия, 2016, 12: 76-81.

52. Devos Y., Romeis J., Luttik R., Maggiore A., Perry J.N., Schoonjans R., Streissl F., Tarazona J.V., Brock T.C.M. Optimising environmental risk assessments. Accounting for biodiversity and ecosystem services helps to translate broad policy protection goals into specific operational ones for environmental risk assessments. EMBO Reports, 2015, 16(9): 1060-1063 (doi: 10.15252/embr.201540874).

53. Leung K.M.Y., Dudgeon D. Ecological risk assessment and management of exotic organisms associated with aquaculture activities. In: Understanding and applying risk analysis in aquaculture. FAO Fisheries and Aquaculture Technical Paper 519 /M.G. Bondad-Reantaso, J.R. Arthur, R.P. Subasinghe (eds.). FAO, Rome, 2008: 67-100.

54. Gworek B., Baczewska-Dąbrowska A.H., Kalinowski R., Górska E.B., Rekosz-Burlaga H., Gozdowski D., Olejniczak I., Graniewska M., Dmuchowski W. Ecological risk assessment for land contaminated by petrochemical industry. PLoS ONE, 2018, 13(10): e0204852 (doi: 10.1371/journal.pone.0204852).

55. Kapustka L. Limitations of the current practices used to perform ecological risk assessment. Integrated Environmental Assessment and Management, 2008, 4(3): 290-298 (doi: 10.1897/IEAM_2007084.1)

56. Cabell J.F., Oelofse M. An indicator framework for assessing agroecosystem resilience. Ecology and Society, 2012, 17(1): 18 (doi: 10.5751/ES-04666-170118).

57. Анненков Б.Н., Егоров А.В., Ильязов Р.Г. Радиационные аварии и ликвидация их последствий в агросфере /Под ред. Б.Н. Анненкова. Казань, 2004.

58. Костюк В.И., Вихман М.И., Кашулин П.А., Шмакова Н.Ю., Жиров В.К., Кизеев А.Н. Влияние избыточных доз меди на фотосинтетический аппарат растений овса. Агрохимия, 2005, 12: 51-58.

59. Loi N.N., Sanzharova N.I., Shchagina N.I., Mironova M.P. The Effect of cadmium toxicity on the development of lettuce plants on contaminated sod-podzolic soil. Russian Agricultural Science, 2018, 44: 49-52 (doi: 10.3103/S1068367418010111).

60. Лой Н.Н., Санжарова Н.И., Миронова М.П. Оценка фитотоксического действия Сd на кормовые бобы при их выращивании на разных типах почв. Агрохимия, 2015, 1: 89-96.

61. Prakash M.G.N., Chung I.M. Impact of copper oxide nanoparticles exposure on Arabidopsis thaliana growth, root system development, root lignification, and molecular level changes. Environmental Science and Pollution Research, 2014, 21: 12709-12722 (doi: 10.1007/s11356-014-3210-3).

62. Фригидов Р.А., Фригидова Л.М., Анисимов В.С., Санжарова Н.И., Анисимова Л.Н., Дикарев Д.В. Оценка критических уровней содержания $\mathrm{Zn}$ в выщелоченном черноземе с использованием тест-растений ячменя и кормовых бобов. Агрохимия, 2017, 3: 69-78.

63. МУ 2.6.5.010-2016. 2.6.5. Атомная энергетика и промышленность. Обоснование грании и условия эксплуатации санитарно-защитных зон и зон наблюдения радиационных оббектов. Метод. указ. (утв. ФМБА России 22.04.2016). М., 2016.

64. Pasquill F. Atmospheric Diffusion. 2nd ed. John Wiley \& Sons. NY, 1974.

65. Методические указания по расчету радиационной обстановки в окружающей среде и ожидаемого облучения населения при кратковременных выбросах радиоактивных веществ в атмоcферу МПА-98 (утв. приказом Министра РФ по атомной энергии 30.12.1998).

66. ОНД-86. Методика расчета концентраций в атмосферном воздухе вредных веществ, содержащихся в выбросах предприятий (утв. 04.08.1986.). Л., 1987.

67. ДВ-98: Руководство по установлению допустимых выбросов радиоактивных веществ в атмосферу. М., 1999.

68. Спиридонов С.И., Фесенко С.В., Гераськин С.А., Соломатин В.М., Карпенко Е.И. Оценка доз облучения древесных растений в отдаленный период после аварии на Чернобыльской АЭС. Радиационная биология. Радиоэкология, 2008, 48(4): 432-438.

69. Спирин Е.В. Современные проблемы экологической дозиметрии. Радиационная биология. 
Радиоэкология, 2009, 49(3): 338-345.

70. ICRP, 2008. Environmental protection - the concept and use of reference animals and plants. ICRP Publication 108. Ann. ICRP 38 (4-6).

71. WHO/IPCS. Environmental health criteria 210: principles for the assessment of risks to human health from exposure to chemicals. World Health Organization, International Program on Chemical Safety, Geneva, 1999.

72. Онищенко Г.Г., Новиков С.М., Рахманин Ю.А., Авалиани С.Л., Буштуева К.А. Основы оценки риска для здоровья населения при воздействии химических веществ, загрязняющих окружаюшую среду. М., 2002.

73. WHO/IPCS. Environmental health criteria 214: human exposure assessment. Geneva, 2000.

ФГБНУ Всероссийский НИИ радиологии и агроэкологии, 249032 Россия, Калужская обл., г. Обнинск, Киевское ш., 109 км, ФГБНУ ВНИИРАЭ,

e-mail: riar@mail.ru $₫$, forest_rad@mail.ru
Поступила в редакцию 27 июля 2019 года

Sel'skokhozyaistvennaya biologiya [Agricultural Biology], 2020, V. 55, № 3, pp. 468-480

\title{
RISK ASSESSMENT METHODOLOGY FOR AGROECOSYSTEMS IN THE CONDITIONS OF TECHNOGENIC POLLUTION
}

\author{
A.V. Panov, T.V. Perevolotskaya
}

Russian Institute of Radiology and Agroecology, 109 km., Kievskoe shosse, Kaluga Province, Obninsk, 249032 Russia, e-mail: riar@mail.ru ( $₫$ corresponding author), forest_rad@mail.ru

ORCID:

Panov A.V. orcid.org/0000-0002-9845-7572

The authors declare no conflict of interests

Perevolotskaya T.V. orcid.org/0000-0001-8250-5536

Received July 27, 2019

doi: 10.15389 /agrobiology.2020.3.468eng

Abstract

Currently, the world scientific community is faced with the task of identifying and minimizing environmental risks of the impact of anthropogenic factors on ecosystems, especially agricultural ones (A.A. Muzalevsky et al., 2011). The keystone of environmental risk assessment is estimated probability of the adverse effects of various nature (radiation, chemical and biological agents) and prevention of their negative impact. The most common sources of pollution of agroecosystems are precipitation from industrial and transport emissions, industrial wastewater, sewage sludge, organic and mineral fertilizers and plant protection products, dumps of ash, slag, ores and slime (S.C. Barman et al., 2000; Yu.N. Vodyanitsky et al., 2011; E.C. Rowe et al., 2015). Such risks are usually assessed situationally, в The purpose of the presented theoretical research was to develop a unified methodology for assessing agroecological risks caused by anthropogenic pollutants. The developed methodology uses mathematical modeling methods and is based on the principles and criteria ensuring the safety of agricultural ecosystems in conditions of man-made pollution. Atmospheric pollutants are the main source of manmade impact. Temporal patterns of their impact vary from acute (e.g. upon accidents) to chronic that should be taken into account. Agroecosystem productivity, as an integral indicator, is a basic criterion for assessing agroecological risks. The methodology includes a four-step algorithm: i) hazard identification based on available agroecosystem data with identification of the sources and nature of the hazard and key affected components; ii) impact assessment by measuring or calculating its intensity, duration, and mode of exposure; iii) a dose-effect assessment by a relationship between the degree of the impact and the probability of its negative consequences; iv) risk characterization, including reliability analysis of the obtained data, estimates of risk from individual factors and their combinations, and calculation of a probability of adverse effect for each agroecosystem component. The choice of a method for assessing agroecological risks (deterministic, probabilistic of the 1st and 2nd type, and integral probabilistic) is substantiated based on the indicator pools, risk criteria and the degree of technogenic impact. Risk characterization includes its classification in terms of an environmentally acceptable level as per maximum allowed concentrations and semi-lethal doses (LD50). For each step, risk uncertainties are accounted. Agroecological risk assessment algorithm includes i) database analysis and selection of agent-specific and exposure-specific values of the effects; ii) estimates of meteorological parameters of pollutant diffusion under specific release conditions; iii) calculated or experimental estimates of pollutant deposition on the ground depending on peculiarities of the impact; iv) calculation or experimental assessment of radionuclide or chemical toxicant contaminations; v) calculation or measurement of the effects of radionuclides or chemical pollutants on the agroecosystem components. The proposed approaches to assessing agroecological risk are applicable to a wide class of environmental problems.

Keywords: agroecosystem, agricultural products, heavy metals, radionuclides, technogenic factor, agroecosystem components, impact level, dose-response relationships, mathematical models. 